\title{
UN FACCIOSO MÁS Y ALGUNOS FRAILES MENOS. NOVELA E HISTORIA EN EL CENTENARIO DE GALDÓS
}

ISABEL ROMERO TABARES ${ }^{1}$

RESUMEN: Este artículo es un breve comentario de uno de los Episodios Nacionales quizás menos conocido de Benito Pérez Galdós. Galdós recrea en él la matanza de religiosos de julio de 1834, ocurrida en el contexto de la I Guerra Carlista y en el año de la epidemia de cólera que asoló España (especialmente, Madrid). El profesor Manuel Revuelta escribió sobre esos asesinatos, especialmente los de 14 jesuitas que perecieron en el Colegio Imperial de San Isidro. En este breve trabajo he querido relacionar la novela de Galdós con la investigación de nuestro querido profesor.

PalabRas CLAVE: Jesuitas; matanza; anticlericalismo; carlismo; liberales; epidemia de cólera.

\section{One more Faccious and some Fryas less. Novel and History on Galdós' first Centenary}

ABStRACT: This article approaches to one of the, perhaps, lesser-known Episodios Nacionales of Benito Pérez Galdós. Galdós recreates the massacre of members of clergy which took place in July 1834, in the context of the First Carlist War and during the year the cholera epidemic devastated Spain (especially Madrid). Professor Manuel Revuelta wrote about these murders and focused on 14 Jesuits who perished in the Imperial College of San Isidro. My aim in this short paper is to relate Galdós's novel with the research of our dear professor.

KEY WORDS: Jesuits; slaugther; anticlericalism; Carlism; liberals; cholera epidemic.

1 Profesora del Departamento de Filosofía. Universidad Pontificia Comillas. Correo electrónico: iromero@comillas.edu. 
Nos encontramos ante el último libro de la Segunda Serie de los Episodios Nacionales de Benito Pérez Galdós². Este iba a ser, por decisión del propio autor, el último libro de la saga. La historia acaba en 1835 y Galdós consideraba que los años posteriores estaban demasiado cercanos a él y a su público y eso le quitaba perspectiva.

Afortunadamente, pronto cambió de opinión, pensando que la Historia (con mayúsculas) era una herramienta didáctica de primer orden para incidir en la educación de sus conciudadanos que se dirigían, inexorablemente, al siglo XX, con muy poco conocimiento de los hechos y de las causas de los mismos. Galdós quería ser muchas cosas: literato, retratista, sociólogo, erudito..., pero, sobre todo, quería contribuir a que la gente fuese menos ignorante, menos crédula, menos manipulable... Toda su obra gigantesca puede medirse por ese parámetro personal.

Nos ocupa ahora un relato que prevé, e incluso metaforiza, el enfrentamiento entre las dos Españas, presentadas en los personajes de dos hermanos, Salvador Monsalud, primero afrancesado y después liberal, y su hermanastro, Carlos Navarro, alias Garrote, primero realista y después carlista reaccionario.

Monsalud intentará, hasta el último libro, que su hermano acepte su consanguinidad -cosa que no logra-, como primera vía de reconciliación que, dada la negativa de Navarro, es, de todo punto, inviable.

Al final del libro, Garrote se siente lo suficientemente bien como para emular a Zumalacárregui, poniéndose al frente de todo el ejército carlista. Una vez más, Salvador se echará al monte para encontrar a su hermano y cuando consigue dar con él le encuentra gravemente enfermo, con medio cuerpo paralizado. Le recoge le lleva a la casa del cura de Elizondo; allí coinciden con el infante Don Carlos, que llega a tierras navarras para encontrarse con Zumalacárregui y ponerse al frente de su ejército para marchar sobre Madrid y reclamar su derecho al trono. Garrote no consigue sobrevivir a su enfermedad y muere sin haber perdonado ni a su mujer, ni a su hermano. Salvador abandona finalmente los dominios carlistas y regresa a Madrid para tomar a Sola por esposa, con lo que finaliza esta segunda serie de los Episodios Nacionales.

Está claro que las simpatías de Galdós están con Monsalud, a pesar de que este no está pintado con trazos heroicos. Navarro se adecua más a la pintura del héroe tradicional: convicciones firmes, lealtades inconmovibles, nula evolución. Morir paralizado resulta una metáfora reveladora.

2 Utilizaré la edición digital de la novela que puede encontrarse en http://www. textos.info/. Texto 1541. 
Sin embargo, los estudios actuales sobre la figura del «héroe» ponen de relieve que, lo auténticamente heroico (humano) es una condición que lleva a la evolución personal, ineludiblemente. El personaje heroico no regresa de su misión o búsqueda igual que salió. Podría decirse, por tanto, que, para Galdós, Salvador Monsalud es más «héroe» que Carlos Navarro.

A través de esta confrontación fraterna, el novelista nos muestra las dos posiciones en las que se coloca la sociedad española: liberales y absolutistas, primero; isabelinos y carlistas después.

\section{1. «UN FACCIOSO MÁS»}

Cuando empieza la novela, al rey Fernando VII le queda un año de vida, antes de que su esposa María Cristina se haga cargo de la regencia. También se describen los últimos días y la muerte de aquel «aciago monarca», dándole consistencia trágica a la «España escindida», asentando las dos Españas y dejando como legado una guerra civil.

Al futuro jefe de gobierno, Martínez de la Rosa, se debe, precisamente, la mitad del título de la novela. Es la expresión que pronuncia cuando se entera de que el Pretendiente, Carlos $\mathrm{M}^{\mathrm{a}}$ Isidro de Borbón, había entrado en España por Elizondo: «un faccioso más» (Martínez, 1838, 221-222)3. La dijo, al parecer, en tono displicente, sin advertir que España entraría en una guerra civil. Galdós no cita la expresión en esta novela; sí lo hace en el tomo de Cánovas, de la Quinta Serie, donde el personaje de don Segismundo se despacha a gusto criticando a Martínez de la Rosa y sus sucesores:

Detesto la guerra civil dinástica, y es tan vivo mi odio a ese medio siglo de lucha fratricida sin gloria y sin fruto, que nada encuentro en él que pueda contentarme. Tanto me amarga esa guerra que me incomodan hasta las victorias, me carga el heroísmo y me revientan los laureles. Para mí, la contienda de familia debió quedar acabada y finiquita el mismo 34, a los pocos meses de entrar en España por Elizondo el inmenso mentecato don Carlos María Isidro, cuando Martínez de la Rosa lanzó la frase de «un faccioso más». En este desdichado país no había entonces sentido político ni militar sentido, ni el vigoroso estímulo de la conservación nacional. Por la flaqueza de estos sentimientos, los españoles no supieron

3 La frase se hizo célebre, dadas las nefastas consecuencias que tuvo para el país la entrada de ese "faccioso». Dos años después, en el Diario de las sesiones del Congreso de Diputados, en la legislatura de 1838, se recoge la defensa que el propio Martínez de la Rosa (que ya no era Jefe de Gobierno) hace de su expresión, o al menos, la justificación, minimizando el tono de displicencia. (Madrid. Oficina de D. Tomás Jordán, 1838, Tomo I, pp. 221-222). 
extirpar el mal aplicando con dureza implacable el procedimiento quirúrgico. La querella dinástica se hizo crónica ... (Pérez Galdós: Cánovas )

Martínez de la Rosa asumiría el gobierno en 1834 y lo dejaría al año siguiente. Duró muy poco en el poder esta hombre ecléctico y moderado que no convenció a nadie y por cuya blanda política recibió el mote de «Rosita la Pastelera».

La frase con la que Martínez de la Rosa pretendía minusvalorar al Pretendiente definía, sin embargo, un aspecto tan importante de la situación política española que condicionaba a todos los demás: la confrontación acérrima entre dos mentalidades que afectaban a todas las dimensiones de la vida y organización social: educación, economía, libertades, organización del territorio, etc. La abundancia de elementos extremistas en los dos bandos, la falta de información y formación del pueblo, los intereses creados en todos los estamentos y, desde luego, la falta de líderes competentes hacía casi imposible el diálogo necesario para cambiar las estructuras socio económicas y políticas del Antiguo Régimen al nuevo modelo que exigía el siglo.

En todo ello, la cuestión religiosa no era un asunto baladí. Detrás de todos los intentos de avance, en uno u otro sentido, latía el sentimiento religioso, el papel del clero, la política vaticana... A pesar de su blandura, Martínez de la Rosa empezó su gobierno suprimiendo definitivamente la Inquisición. Era la cuarta vez que se intentaba. También proclamó una ley de libertad de imprenta que, aunque no total, fue suficiente para que el debate, la sátira y la información, más o menos rigurosa, fuesen de dominio público.

Galdós dedica un gran párrafo de su novela a dejar claro la falta de unidad que tenían los liberales, los «libres» como se les apodaba entonces. Se trata de D. Eugenio Aviraneta que responde así al capitán Rufete:

Los libres, como usted dice, y los liberales, como los llamo yo, están tan divididos que no oye usted dos opiniones iguales si habla con ellos. Hay multitud de tontos a quienes no se puede arrancar de la cabeza lo del mejor de los códigos hay algunos solemnes pillos que por malicia y por tener poder ante la canalla, gritarán, si les dejan, constitución o muerte; hay el grupo de los anilleros ${ }^{5}$ o de los sabios, que reniegan de todo si no les dan las dos Cámaras con Carta, a la francesa, y aun creo que alguien quiere que haya tres Cámaras, por no parecerle bastante dos. Unos piden que haya mucha religión sin dejar de haber libertad, mientras los iluminados desean acabar con la gente de cogulla y quemar los conventos, para

$4 \quad$ Así se llamaba a la Constitución de 1812.

5 Miembros de la Sociedad del Anillo (llamada así porque sus miembros llevaban un determinado anillo para reconocerse), entre los que se encontraba el propio Martínez de la Rosa y que promovían la existencia de dos Cámaras legislativas. La Constitución de 1812 sólo contemplaba una. 
que suprimidos los nidos no haya miedo de que vuelvan los pájaros. Yo he tanteado aquí y allí y he encontrado asperezas que no es fácil suavizar, y antagonismos que no es posible vencer. Martínez de la Rosa, Toreno, Burgos y comparsa se niegan a todo lo que sea revolución, (...) y los exaltados juran y perjuran que no hay más Constitución que la del 12 en todo el globo terráqueo, y que ellos la harán triunfar, pese a quien pese. Vamos, esta es una casa de fieras, y yo digo que convendría que estallase la guerra y viniesen grandes peligros para que entonces se unieran tantas voluntades y se llegara a un acuerdo en lo de la Constitución definitiva, aunque hubiese siete Cámaras y cuatrocientas alcobas. (p. 46. El subrayado es mío)

Precisamente del problema religioso trata la novela de Galdós, pues el escritor es consciente de la importancia del tema en la sociedad española y de las repercusiones del mismo.

El profesor Manuel Revuelta muestra ya en el índice de uno de sus principales libros (Revuelta, 2005), los conflictos fundamentales que aquejaban al estamento clerical y religioso:

- Sobreabundancia del clero.

- Los inconvenientes de la vieja estructural clerical.

- Signos de rutina y atonía moral.

- Despliegue de las congregaciones religiosas.

- Controversia sobre la misión del sacerdote.

La Iglesia española, aquejada por enormes problemas, muchos de los cuales derivaban de su propio inmovilismo, se veía interpelada desde muchos ámbitos y carecía, en general, de respuestas convincentes. No obstante, hay muchos clérigos liberales, incluso obispos, que buscan adaptar las estructuras eclesiásticas a las nuevas necesidades y demandas. Sin embargo, todos serán criticados por exceso o defecto. La única corriente que la defienda a ultranza será precisamente el carlismo, lo que provocará una reacción todavía más agresiva por parte de los liberales radicales.

A decir de M. Revuelta, durante los años de la regencia de María Cristina de Borbón (1833-1840), las antiguas órdenes religiosas conocen su definitiva ruina. "La trayectoria de esta exclaustración quedará ligada estrechamente a la compleja trama política de una España liberal traumatizada por la guerra civil. Influyen por eso en esta exclaustración tres elementos nuevos: la guerra carlista, la división del partido liberal en los partidos moderado y progresista, y la violencia de las insurrecciones provinciales y de los motines callejeros, instigados por grupos revolucionarios. El carlismo sirve ahora de pretexto para lanzar sobre los religiosos, en general, la inculpación de infidelidad a Isabel II, a pesar de que existían no pocos clérigos que eran ardientes liberales»(Revuelta, 2005, 123). 


\section{ALGUNOS FRAILES MENOS}

Precisamente son los radicalismos, el afán de poder y la instigación a la violencia los enemigos que hacen imposible la estabilidad y la paz.

La segunda parte del título se refiere a la matanza de religiosos que sucedió en Madrid el 17 de julio de 1834.

En ese tiempo se abate sobre España una epidemia de cólera procedente de la India. Madrid, como ciudad más populosa, sufre las peores consecuencias. Madrid es una urbe de 200.000 habitantes, aumentados en esa fecha por gentes que llegaban huyendo de revueltas provinciales. Su alcantarillado era precario; la convivencia de las familias con los animales era habitual, sobre todo en los barrios pobres; las calles se usaban como urinarios públicos; la mendicidad era un drama humano constante.

Durante los primeros días del mes de julio, la prensa intentó disimular la situación, pero fue en vano. La familia real abandona la capital y se traslada a La Granja para alejarse de la epidemia. Fallecen más de 3.500 personas.

A esta desgracia se unen los movimientos de las tropas carlistas que, lideradas por Zumalacárregui, representan ya una amenaza real para el territorio español.

Las autoridades sanitarias tomaron medidas: se demolieron chabolas y se expulsó a los vagabundos, sin miramientos; se prohibió la cría de animales en las viviendas y se recogieron las basuras..., pero todo fue insuficiente.

Galdós cuenta los hechos con bastante detalle. Es de suponer que las fuentes documentales fueron los periódicos de la época, así como las memorias de Antonio Alcalá Galiano (Alcalá 1878; De la Fuente 1874 y Pérez 2019).

El 17 de julio se propaga el rumor de que hay personas envenenando el agua de las fuentes y pozos y, por tanto, causando el cólera. Dice Galdós:

El pueblo es conductor admirable de las buenas como de las malas ideas, y cuando una de estas cae bien en él, le gana por completo y le invade en masa. Bien pronto la harpía individual fue una harpía colectiva, un monstruo horripilante que ocupaba media calle y tenía cuatrocientas manos para amenazar y doscientas bocas para decir: ¡Cosas malas en el agua!

Quien no piensa nunca, acepta con júbilo el pensamiento extraño, mayormente si es un pensamiento grande por lo terrorífico, nuevo por lo absurdo. Aquel día habían ocurrido muchas defunciones. Varias familias tenían en su casa un muerto o agonizante. En presencia de una catástrofe o desventura enorme, al pueblo no le ocurren las razones naturales de lo que ve y padece. Su ignorancia no lo permite saber lo que es contagio, infección morbosa, desarrollo miasmático. ¿Y cómo lo ha de saber la ignorancia, si aún lo sabe apenas la ciencia? El pueblo se ve morir con síntomas y caracteres espantosos, y no puede pensar en causas 
patológicas. Cristiano de rutina, tampoco puede pensar en rigores de Dios. Bestial y grosero en todo, no sabe decir sino: ;Cosas malas en el agua!. (pp. 202-203)

Los grupos, empuñando armas caseras, empiezan su macabro itinerario por el Colegio Imperial de San Isidro para castigar a los jesuitas.

Galdós nos había presentado en la novela al jesuita P. Gracián, un hombre culto y a la vez un hombre de fe, relacionado, a su vez, con otros personajes. Tenía un solo rasgo de devoción sentimental: encargaba traer desde Cataluña, tierra de la roca de Manresa donde vivió San Ignacio. Con ella cubría el suelo de su habitación y dormía, a veces, sobre ella, como gesto de austeridad y unión con su santo fundador.

Después de acuchillar a varios jesuitas, los exaltados vecinos dan con el P. Gracián en el coro donde lo asesinan. Ya habían descubierto la tierra de Manresa que, por supuesto, casaba, en sus desvaríos, con los «polvos» venenosos que los frailes abrían arrojado al agua.

Quince jesuitas mueren a manos de los grupos violentos que siguen su camino yendo a San Francisco el Grande para hacer su espantoso trabajo con los frailes franciscanos y después con los mercedarios en San José. Después de doce horas de locura homicida, el resultado fue de 73 religiosos muertos y 11 heridos. Era la primera vez que la Iglesia era golpeada así por sus propios fieles.

Las autoridades municipales y militares no hicieron gran cosa para defender a los religiosos. Gobernaba ya Martínez de la Rosa y el 18 de julio (los disturbios seguían desarrollándose) el general anunció el estadio de sitio; el 19 detiene y encarcela al capitán general Martínez de San Martín, que contaba con 9.000 hombres para detener o evitar los asaltos; obligó a dimitir al gobernador civil y al alcalde, como máximos responsables de la milicia urbana que había tenido abundante participación en los hechos. Pero ninguno de los altos responsables fue juzgado. Se sometió a juicio a 79 personas, de las que dos fueron condenadas a muerte, por robo, no por asesinato; el resto, todas personas humildes, sufrieron penas diversas.

El juicio de los historiadores sobre estos hechos no es coincidente. Básicamente, hay dos interpretaciones: la primera considera que el episodio de violencia fue espontáneo, fruto del miedo de la gente a la enfermedad, aunque un miedo «dirigido» por la campaña anticlerical que la prensa liberal mantenía.

La otra interpretación dice que los hechos del 17 de julio de 1834 obedecieron a una conspiración ideada por los grupos liberales más radicales, no necesariamente masones, opinión seguida por Revuelta (2001, p. 2.570 y Egido, 2004). 
De hecho, el mismo Galdós sugiere esta posibilidad. Días antes de los sucesos, el P. Gracián es advertido por uno de los personajes de que se está tramando una acción contra los religiosos, pero sin demasiada importancia:

Según mi informe - añadió este- y son informes verdaderos, procedentes del horno mismo donde se cuecen tales pasteles, la broma, susto o como queramos llamarlo, no pasará a mayores. Los patriotas sólo quieren manifestar su antipatía a Vuestras Reverencias y protestar de la protección que Vuestras Reverencias dan al carlismo. Es cierto que esa protección existe por la misma naturaleza de las cosas y los antecedentes de las personas. ¡Hecho lógico, imprescindible, abrumador! Es cierto también que el régimen liberal no puede coexistir con el carlismo, de donde resulta un antagonismo imponente entro dos hechos, entre dos verdades, entre...

Pero algún día, Señor y Padre, ha de haber una como la de San Quintín, porque o Vuestras Reverencias dejan de amparar a los carlistas, o los carlistas absorben al liberalismo, o el liberalismo se los traga a ellos y a Vuestras reverendísimas Paternidades. (p. 195)

Antes de esta advertencia, el P. Gracián escucha en la calle esta coplilla, unos versos liberales y anticlericales de los que algunos historiadores se hacen eco:
¡Muera Cristo,
viva Luzbel!
¡Muera D. Carlos,
viva Isabel!

Sin embargo, no le da demasiada importancia, como persona acostumbrada a esas manifestaciones. El anticlericalismo parece formar parte del ambiente.

El profesor Revuelta estudia en un excelente artículo esta corriente extensamente difundida en el siglo XIX y asociada a muchos factores (Revuelta, 2002). El hecho de que Galdós destaque la matanza de frailes de 1834 (como es conocida en la Historia) como hecho histórico inserto en sus Episodios Nacionales, indica la importancia que le da el escritor. Da la impresión de mostrar el atolladero en que se encuentra el país (o al menos se encontraba en 1834) sin una dirección clara que marque el rumbo.

Galdós achaca esta falta de dirección a la confusión ideológica que muestran los liberales moderados, grupo en el que cabe todo, pero en el que, por eso mismo, no se encuentra nada claro.

En el seno de este partido, que en un tiempo se llamo de los sabios y en sus albores se llamo de los anilleros, había gente de gran mérito, aleccionados los unos en la práctica estéril de liberalismo, otros algo amaestrados en el arte 
político que faltaba a los liberales. Ellos fueron los primeros maquiavélicos ante quienes sucumbio la inocencia angélica de aquellos candorosos doceañistas que principiaban a no servir para nada. A falta de principios tenían un sistema, compuesto de engaño y energía. Su credo político fue una comedia de cuarenta años. Su éxito debiose a haber vigorizado el principio de autoridad, y su descrédito o impopularidad a haber impedido el desarrollo progresivo de las ideas. En religión eran volterianos, y en sus costumbres privadas enemigos de la templanza; pero tenían un coram vobis de santurronería que hacía el efecto de ver la silueta de Satanás en la sombra de un confesonario. Uno de los primeros elementos de fuerza que allegaron fue el clero, a quien adulaban, disponiéndose, no obstante, a comprar por poco dinero sus bienes, cuando los progresistas los arrancaron de las manos que llamaban muertas. (p. 198)

No podemos olvidar que el protagonista de esta historia es Salvador Monsalud, un hombre que ha evolucionado hasta ser un liberal, pero, ante todo, un hombre que se ha llenado de compasión y humanidad y, por eso, dispuesto a los mayores sacrificios para reconciliarse con su hermano, cada vez más enfermo del cuerpo y del alma.

El propio Galdós se muestra a través de este personaje que no se convierte en un radical fanatizado, pero que tampoco es un hombre tibio. En él se advierte la tristeza constante por su vida de sin sabores y obstáculos, pero también la nostalgia de la vida del pueblo, sencilla, antes de ser contaminada por ideas que anteponen la confrontación al diálogo y la felicidad.

Finalmente encuentra el amor de Sola y se casa con ella. Con este matrimonio feliz termina la vida novelesca de este personaje a quien ya no volveremos a encontrar en los Episodios galdosianos. Su peripecia vital llega a una felicidad moderada, quizás lo que el escritor desea para la gente del pueblo a quien observaba, admiraba y amaba.

\section{REFERENCIAS}

Alcalá Galiano, A. (1878). Recuerdos de un anciano. Madrid: Víctor Sáiz

De la Fuente, V. (1874). Historia de las sociedades secretas antiguas y modernas en España. Madrid: D.R.P. Infante.

O’Neill, C. E. y Domínguez, J. M. (2001). Diccionario histórico de la Compañía de Jesús. Madrid: Universidad P. Comillas.

Egido, T. (Coord.) (2004). Los jesuitas en España y en el mundo hispánico. Barcelona: Marcial Pons.

Martínez de la Rosa, F., (1838). Diario de las sesiones del congreso de los diputados. Madrid: Oficina de D. Tomás Jordán.

Pérez Galdós, B., Cánovas. Recuperado de: https://books.apple.com/es/book/c\%C3\% A1novas/id1483795710 
Pérez Roldán, C. (2019). La matanza de frailes de 1834. Prensa y propaganda. La Albolafia. Revista de Humanidades y Cultura, 153-176. Recuperado de https://webcache.googleusercontent.com/search?q=cache:CTh8yZzXFnoJ:https://dialnet. unirioja.es/descarga/articulo/7193389.pdf $+\& c d=7 \& h l=e s \& c t=c l n k \& g l=e s$

Revuelta, M. (1999). El anticlericalismo español en sus documentos. Madrid: Ariel.

Revuelta, M. (2001). Matanza de frailes. En Ch. O’Neil y J. Ma Domínguez (Dirs.), Diccionario Histórico de la Compañía de Jesús. Biográfico-Temático (pp. 2569-2570). Roma-Madrid: Instituto Histórico de la Compañía de Jesús-U. P. Comillas.

Revuelta, M. (2002). El anticlericalismo español en el siglo XIX. En P. Aubert (Ed.), Religión y sociedad en España (siglos XIX-XX) (pp. 155-178). Madrid: Casa de Velázquez.

Revuelta, M. (2005). La Iglesia española en el siglo XIX: desafíos y respuestas. Madrid: Universidad Pontificia Comillas. 